\title{
Sudden confusion and cognitive decline due to acute infarction of the anterior thalamic nucleus (ANT) - a
} case report

\begin{abstract}
A 76-year-old man presented with sudden behavioral changes and cognitive decline. His clinical presentation was characterized by impaired short-term memory, strange behavior, disorientation, impaired executive function, and withdrawal. MRI of the head showed an infarcted lesion in the right thalamus, confined to the anterior thalamic nucleus. According to the characteristics of the cognitive network and evidence from different clinical and experimental studies, infarction in this critical part of the anterior thalamic nucleus can cause disruption of basal ganglia-thalamo-prefrontal circuit, resulting in confusion and cognitive decline. The combination of clinical symptoms, neuroimaging and temporal findings led to the final diagnosis of strategic infarct vascular dementia $(\mathrm{VaD})$ subtype (SIVaD).
\end{abstract}

Volume II Issue 5 - 202 I

\author{
Chunhui Yang,' Junyi Zhang, ${ }^{2}$ Jingxia Li, ${ }^{3}$ Qin \\ $\mathrm{He}^{2}$ \\ 'Beijing Ivheart Health management Center, China \\ ${ }^{2}$ Department of Neurology \& Neurosurgery, People's Hospital \\ of Ordos Dongsheng District, China \\ ${ }^{3}$ Department of Emergency, People's Hospital of Ordos \\ Dongsheng District, China
}

Correspondence: Chunhui Yang, Beijing Ivheart Health
management Center, China, Email chunhuiyang20I8@gmail.com

Received: August 20, 202I | Published: September 02, 2021

\section{Introduction}

The type of dementia, that cognitive decline due to brain infarction at strategic sites has been identified as strategic infarct vascular dementia (VaD) subtype (SIVaD). ${ }^{1,2}$ All-important sites are major components of the Papez circuit. ${ }^{3-12}$

The projection of the Papez circuit consists of the fornix, papillary bodies, papillary tracts of the thalamus, anterior thalamus, cingulate cortex, and cingulate tract. The concept that the Papez circuit is primarily implicated in memory function is widely accepted..$^{12}$ Anterior nucleus of thalamus (ANT) is an important nucleus of the Papez cortical network species. When this nucleus and its connection to the hippocampus is disrupted, then human memory is disrupted. ${ }^{1-6,7-10,11-14}$ The ANT includes the anteromedial (AM), anterolateral (AV), and anterolateral (AD), all of which are primarily irrigated by the canalicular cerebral arteries.

In addition, Damage to different thalamic nuclei and their connecting pathways can also cause other cognitive impairments and significant behavioral changes, depending on the nuclei involved and their connections, such as interruption of the thalamic-prefrontal connections associated with the basal ganglia-thalamo-prefrontal circuit also exhibits symptoms of executive dysfunction. ${ }^{15}$

In this report, a typical case of acute behavioral changes and cognitive decline due to damage to the ANT and its associated connections is described, highlighting the anatomical basis associated with the clinical presentation.

\section{Case report}

The patient was a 76-year-old man, right-handed, with 20 years of education. He presented with sudden onset of confusion and behavior change. His main clinical symptoms were impaired shortterm memory, strange behavior, disorientation, impaired executive function, and withdrawal. The patient was living alone. His daughter reported the day before the visit, she was told that her father had failed to show up at a friend's party that he had agreed to attending. When she checked with him by phone, she found he had been hanging around the restaurant for two hours. When asked why not go inside for the party, he said he did not want to join them and drink. That evening, she received four text messages from him, the content of them was blizzard and difficult to understand. She immediately called and asked him where he was now. Apparently, he showed a place orientation error. The daughter immediately called to request that he be sent to the hospital for an examination. The patient denied headache, dizziness, or weakness of limbs.

This patient had a previous history of diabetes for 10 years and had been taking metformin but with poor glycemic control. Aside from that he had no significant medical history.

\section{Physical examination and workup}

The patient's vital sign was normal. His temperature was $98.3^{\circ} \mathrm{F}$ $\left(36.8^{\circ} \mathrm{C}\right)$. And his blood pressure was $116 / 72 \mathrm{mmHg}$.

There were no abnormalities in motor and sensory. No ataxia, dysphasia, or any other language disturbances observed on then eurological examination.

He was unable to identify events and places but was able to recognize family members. The neuropsychological assessment showed MoCA=20/30. On the tests, he was unable to complete the visuospatial/executive performances (his clock drawing test see Figure 2); he failed in the delayed recall, and he was misorientation of time and place as well.

MRI of the brain revealed an infarct in the right thalamus confined to the anterior region (Figure $1 \mathrm{~A} \& \mathrm{~B}$ ). The hippocampi showed bilateral preserved in volume. EEG was normal. Blood workup showed no abnormalities. 


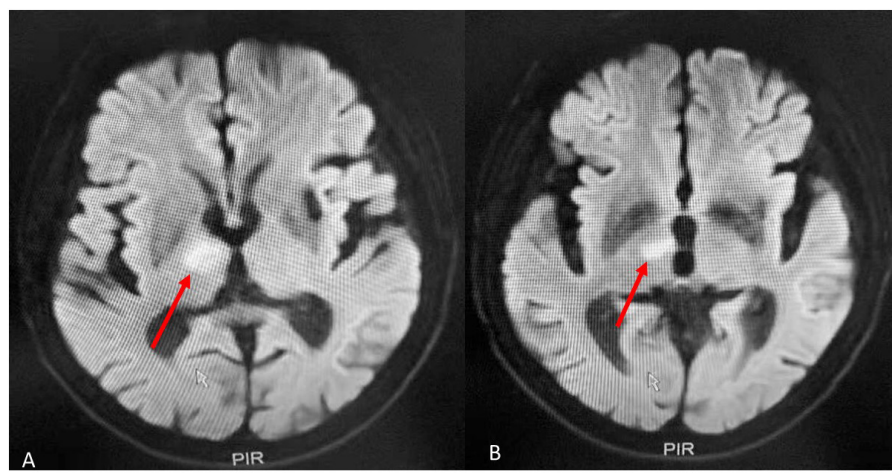

Figure I T2 weighted MRI showing an infarct located in the right anterior nucleus of thalamus (red arrows) (A \& B).

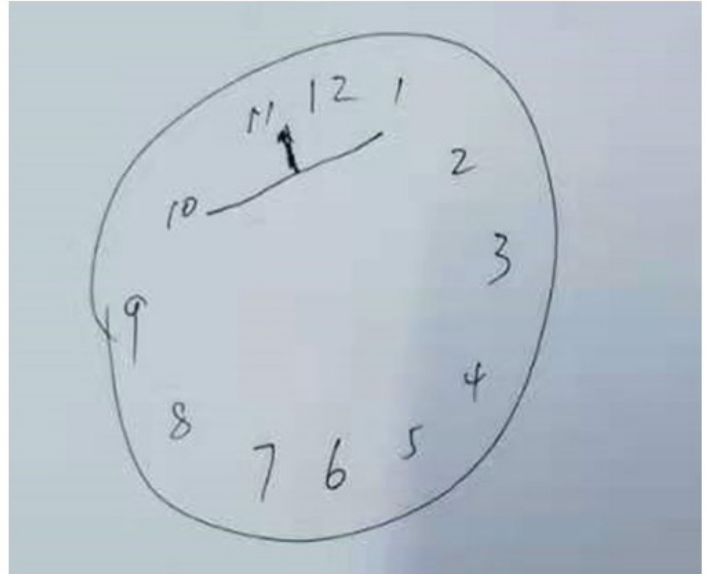

Figure $\mathbf{2}$ The clock-drawing Test showing the inaccurate representation of 10 after II.

\section{Discussion}

According to the NINDS-AIREN criteria, the diagnosis of SIVaD is based on a combination of clinical symptoms, neuroimaging, and sequential findings. ${ }^{22,23}$ The clinical diagnosis of our case was based on the nature of the clinical symptoms, the timing of their appearance and the imaging findings that fully met the NINDS-AIREN criteria. Based on clinical symptoms and imaging studies, the localization diagnosis of the infarction was right anterior nucleus of thalamus (ANT). As one of the important sites of SIVsD, the ANT is frequently mentioned because its blood supply has been already well known. The tuberothalamic artery originated from the middle third of the posterior communicating artery irrigates this area. But it is not present in roughly one third of the normal population, in them its territory is supplied by the paramedian artery. ${ }^{20}$ The tuberothalamic artery is a penetrating artery, and its cause of cerebral infarction is thought to be related to the patient's long-term diabetes mellitus not being well controlled.

Clinical and experimental evidence suggest that since ANT maintains a close association with the hippocampus as well as the prefrontal area, an important cause of the memory impairment observed during thalamic stroke is due to ANT damage..$^{6-9,14,15}$ This was also well documented in our case.

The main feature of the clinical syndrome resulting from the tuberothalamic artery obstacle is manifested by wide spread neuropsychological dysfunction. ${ }^{17,18,20,21}$ In the early stages of infarction, patient's exhibition confusion, appear withdrawn, show disorientation of time and place, lack of insight, apathy, and lack of spontaneity. ${ }^{15,16}$ All these fit perfectly with the clinical presentation of our patient. When attended a friend's party, he preferred to hang around outside the restaurant for two hours rather than go in, giving the reason that he did not want to drink with them. This could also be interpreted as a sudden withdrawal behavior.

Dementia due to thalamic infarction may include impaired executive function, depending on the nuclei involved and their connections. Disruption associated with the basal ganglia-thalamoprefrontal circuit may give rise to executive dysfunction there. ${ }^{15}$ Our patient's poor performance on the visuospatial/executive test is a strong indication of visuospatial processing deficits, suggesting damage to the basal ganglia-thalamus-prefrontal circuitry.

When the lesion in the thalamus is very precisely localized, as shown in this case, where the stroke is confined to the most anterior part of the within the tuberothalamic territory, then a severe impairment of memory but language relatively spared is seen. ${ }^{15}$ This theory may well explain the clinical presentation of our patient who had no language compromised. In general, damage to the right ANT results in less severe cognitive deficiency than the left side. ${ }^{11}$

On MRI, ANT hyperintensities that are greater than $55 \mathrm{~mm}^{3}$ may result in symptomatic cognitive decline, while less than $55 \mathrm{~mm}^{3}$ may not be recognized by clinicians and radiologists. Only half of patients with ANT hyperintensity are diagnosed with vascular dementia or mixed disease. ${ }^{13}$

AS for the prognosis, the SIVaD shows a unique characteristic of causing dementia in an acute way, and once formed at the time of ischemic stroke, it is retained permanently. 2,6

We reported here the clinical, neuropsychological and neuroimaging data of a 76-year-old man with an infarct in ANT. The clinic-geomorphologic correlations of the basal ganglia-thalamusprefrontal circuitry were reviewed and the possible causes of multiple cognitive and behavioral consequences of vascular thalamic lesions were discussed. An overview of the literatures showed dementia caused exclusively by small cerebral infarcts at critical sites was uncommon. In an autopsy study of a large memory clinic, dementia was caused by SIVaD in only 6 of more than 1900 dementia patients. ${ }^{1}$ This one piece of evidence underscores the value of our case study.

In conclusion, the present case was typical of SIVaD, whose main symptoms were confusion, memory impairment and executive dysfunction, appear withdrawn, and disorientation of time and place. As shown by MRI, these manifestations were clearly associated with lesions in the anterior thalamic region, correlated with damage to the basal ganglia-thalamo-prefrontal circuit. ${ }^{10}$

\section{Acknowledgments}

None.

\section{Funding}

None.

\section{Conflicts of interest}

There is no conflict of interest in this case report.

\section{References}

1. Hulette C, Nochlin D, McKeel D, et al. Clinical-neuropathologic findings in multi-infarct dementia: a report of six autopsied cases. Neurology. 1997;48(3):668-672. 
2. Bogousslavsky J, Regli F, Uske A. Thalamic infarcts: clinical syndromes, etiology, and prognosis. Neurology. 1988;38(6):837-848.

3. Gaffan EA, Gaffan D, Hodges JR. Amnesia following damage to the left fornix and to other sites: a comparative study. Brain. 1991; 114:12971313

4. Clarke S, Assal G, Bogousslavsky J, et al. Pure amnesia after unilateral left polar thalamic infarct: topographic and sequential neuropsychological and metabolic (PET) correlations. J Neurol Neurosurg Psychiatry. 1994;57(1):27-34.

5. Saito K, Kimura K, Minematsu K, et al. Transient global amnesia associated with an acute infarction in the retrosplenium of the corpus callosum. J Neurol Sci. 2003;210(1-2):95-97.

6. Schott JM, Crutch SJ, Fox NC, et al. Development of selective verba memory impairment secondary to a left thalamic infarct: a longitudinal case study. J Neurol Neurosurg Psychiatry. 2003;74(2):255-257.

7. Guard O, Bellis F, Mabille JP, et al. Thalamic dementia after a unilateral hemorrhagic lesion of the right pulvinar. Rev Neurol (Paris). 1986;142(10):759-765.

8. Bogousslavsky J, Regli F, Delaloye B, et al. Loss of psychic selfactivation with bithalamic infarction: neurobehavioural, CT, MRI and SPECT correlates. Acta Neurol Scand. 1991;83(5):309-316.

9. Sandson TA, Daffner KR, Carvalho PA, et al. Frontal lobe dysfunction following infarction of the left-sided medial thalamus. Arch Neurol. 1991;48(12):1300-1303.

10. Tatemichi TK, Desmond DW, Prohovnik I, et al. Confusion and memory loss from capsular genu infarction: a thalamocortical disconnection syndrome? Neurology. 1992;42(10):1966-1979.

11. Van der Werf YD, Weerts JG, Jolles J, et al. Neuropsychological correlates of a right unilateral lacunar thalamic infarction. $J$ Neurol Neurosurg Psychiatry. 1999;66(1):36-42.

12. Maria Elisa de Oliveira Lanna, Denise M. Madeira, et al. Vascular Dementia by Thalamic Strategic Infarct. ArqNeuropsiquiatr. 2008;66(2B):412-414.
13. R H Swartz, S E Black. Anterior-medial thalamic lesions in dementia: frequent, and volume dependently associated with sudden cognitive decline. J Neurol Neurosurg Psychiatry. 2006;77(12);1307-1312.

14. Nicholas D Child, Eduardo E Benarroch. Anterior nucleus of the thalamus: functional organization and clinical implications. Neurology. 2013;81(21):1869-1876.

15. Jeremy D, Schmahmann. Vascular Syndromes of the Thalamus. Stroke 2003;34(9):2264-2278

16. Lisovoski F, Koskas P, Dubard $\mathrm{T}$, et al. Left tuberothalamic artery territory infarction: neuropsychological and MRI features. Eur Neurol. 1993;33(2):181-184

17. Graff-Radford NR, Damasio H, Yamada T, et al. Nonhaemorrhagic thalamic infarction: clinical, neuropsychological and electrophysiological findings in four anatomical groups defined by computerized tomography. Brain. 1985;108 (pt 2):485-516.

18. Graff-Radford NR, Eslinger PJ, Damasio AR, et al. Nonhemorrhagic infarction of the thalamus: behavioral, anatomic, and physiologic correlates. Neurology. 1984;34(1):14-23.

19. Von Cramon DY, Hebel N, Schuri U. A contribution to the anatomical basis of thalamic amnesia. Brain. 1985;108 (pt 4):993-1008.

20. Bogousslavsky J, Regli F, Assal G. The syndrome of unilateral tuberothalamic artery territory infarction. Stroke. 1986;17(3): 434-441.

21. Bogousslavsky J, Regli F, Uske A. Thalamic infarcts: clinical syndromes, etiology, and prognosis. Neurology. 1988;38(6):837-848.

22. McKhann G, Drachman DA, Folstein MF, et al. Clinical diagnosis of Alzheimer's disease: report of the NINCDS-ADRDA Workgroup under the auspices of Department of Health and Human Services Task Force on Alzheimer's Disease. Neurology. 1984; 34(7):939-44.

23. Folstein MF, Folstein SE, McHugh PR. "Mini Mental State”A practical method for grading the cognitive state of patients for the clinician. $J$ Psychiatr Res. 1975;12(3):189-98. 